\title{
Ubiquitous Computing: Technological Autonomy or Human
}

\section{Autonomy?}

\author{
Zhu Wenxi \\ Dalian University of Technology
}

\author{
Wang Guoyu \\ Fudan University
}

\begin{abstract}
With the rapid development of information and communication technology (ICT) and sensor technology, ubiquitous computing (or pervasive computing) has become widely used with much convenience to human life. For instance, people can use their electronic devices at hand (e.g., Google glasses or Apple watch) to access information they need. However, this "ubiquitous" service poses challenges to human autonomy. Based on the analysis of the features of pervasive computing, this paper points out the ambiguity between the subject and object of ubiquitous computing and shows technological interventions can affect human autonomy at three levels: technology addiction, the degradation of human capacities, and the reversal of the end and the means caused by the fuzziness of man-machine interface. In other words, ubiquitous computing gives people unprecedented convenience, and it also deprives of their freedom. According to Kant's Theory of Freedom, this article reflects on the relationship between the autonomy of technology and that of humankind.
\end{abstract}

Keywords: ubiquitous computing, technological autonomy, human autonomy, freedom

\section{Introduction}

Apple Inc. announced at his 2015 event held on March 10th when Apple Watch would be launched in April. Such amazing news immediately drew global concern. In the near future, man can answer the phone, do payments, keep in touch with friends, call a cab, book a hotel and so on and so forth anytime and anywhere, only by using a 1.5-inch Smart Watch. The launch of Apple Watch indicates that the Research and Development Institutions that investigates ubiquitous computing has made a breakthrough in terms of developing wearable devices. The idea of ubiquitous computing is firstly presented by Mark Weiser in his essay "The Computer for the 21st Century" in the year of 1991 (Weiser 1991). Soon the international conferences on Pervasive Computing, Ubicomp Computing and Pervasive Computing were held in 1999 and 2000 separately. IEEE Pervasive Computing magazine began to be released in 2002. In the past 20 years, ubiquitous computing has developed dramatically along with sensation and controversy. On one hand, the mainstream scientists accept ubiquitous computing with open horizon. A great deal of projects demonstrate the vitality of ubiquitous computing, for example "Smart Home” project," "Stars of the Future” project and "Easy Living” project of

Zhu Wenxi, Ph.D. candidate, Department of Philosophy, Faculty of Humanities and Social Science, Dalian University of Technology, China; main research field: Philosophy of Technology and Ethics of Technology.

Wang Guoyu, Ph.D., Professor, Department of Philosophy, Fudan University, China; main research field: Philosophy of Technology and Ethics of Technology.

This article is funded by: (1) Research on High-Tech Ethical Issues, the National Social Science Fund of China (12 \& ZD17); (2) Responsible Innovation Research, Innovation Team of Colleges and Universities in Liaoning Province (WT2015002). 
Microsoft, "Sentient Computing” projects of AT \& T laboratory and the University of Cambridge, '”WebSphere Everyplace” project of IBM, Portolano project of the University of Washington. On the other hand, there have been still some concerns about such an uncertain technology, as saying goes "the backside of the Gospel will be a disaster" (Li 2003, 41). Die Zeit, a well-known newspaper in Germany, revealed in 2005 that some commercial giants, such as Metro and Wal-Mart, had embedded RFID Chip in their products to obtain the likes and dislikes of the customers. Otherwise, the newspaper also called on the EU to intervene in the Chip-embedding of manufacturers and distributors in order to prevent them from abusing of technology and from interfering with the privacy rights of citizens. In 2010, Las Vegas and Atlantic City issued a joint statement, announced that wearable smart devices (such as Google glasses) are would not be allowed to be taken into the Casino. The main reason for this ban is that these smart devices may have the ability of self-calculation. This sort of ability will undermine the original devices of the Casino and trigger unpleasant troubles in gambling activities (Cui 2014, 54). In addition, the convenience and quickness of ubiquitous computing attract people's attention all the time. Man indulges in virtual world and isolates himself from the real world. Being addicted to ubiquitous computing technology degrades human's capacities and makes them "awkward." In other words, as ubiquitous computing gives people unprecedented convenience, people cannot avoid losing their freedom gradually. Besides, security-, privacy-, environmental, and ethic issues caused by ubiquitous computing have become the theme of ethical reflection.

\section{The Concept and Features of Ubiquitous Computing}

Ubiquitous Computing described in terms of Pervasive Computing combines various technology, including information and communication technology (ICT), sensor technology, manufacturing technology of small calculation equipment. With smart devices embedded in daily environment, users can interact with the computer, operating by using any device in any location and in any format so as to make the computer invisible from users' sight and the users can focus on their task itself instead of the computer. Ubiquitous computing by computer-, communication- and digital media technology, makes it possible to integrate the physical world in which we are living in, the virtual world and the information space together as the whole. Under this circumstance will computing devices through the global network provide users with more personalized services (Zhu 2009). According to Weiser who put forward the idea for the first time, the vision of ubiquitous computing can be reduced to the following elements: considerably fewer hardware components; adaptiveness of the system; the self-organization of the system; the system is aware of context (Wiegerling 1989, 1-4). Thus, it is capable of interpreting situations, by which technology merges to invade a field traditionally filled by cultural studies and hermeneutics respectively. The physical environment is augmented by information systems; permanent mobile or ubiquitous availability of information systems and linking of local and global information. With the development of computer technology, the features of ubiquitous computing appear obvious, which emphasize the function of accessing information "anytime, anywhere" and "transparently." In other words, the most important features of ubiquitous computing are thought to be "ubiquitous" and "transparent" (Shen 2005, 42). "Ubiquitous" means users can access information and services provided by the system at any device in any location and in any format without sitting in front of computers in times of desktop computing. "Transparent" is intended to express that users obtain information and service naturally and easily, even though they are not aware of the case. Besides, self-adaptability as the basis for people-oriented, is also viewed to be another feature of ubiquitous computing. Such sort of feature signifies that the system can effectively perceive the 
changes, which happen in physical or information space in the location of equipment or in people's behavior; and then adjust its behavior to adapt to the changes.

Though ubiquitous computing develops now in its early stages, it has already obtained a remarkable achievement. A mobile phone can be regarded as a handheld terminal with the help of which we can make telephone calls, browse the website, send and receive messages, and so on. As you can imagine, in higher stages which described as Ambient Intelligence, the system will be able to self-organize, self-induct, and self-coordinate between different systems. It will also be capable of providing people with the information and services they need according to the preferences they once showed. That is, if the system knows the location of the user or the time of his vacation, it will make a schedule for him in advance and shut down the devices or set call reminders automatically while the user is not in. If the user inputs some basic information, such as price, material, warmth retention property, then the information about price will be showed while checkout; information about material will be saved in washing machine and ironing machine in order to set a suitable temperature by washing or ironing; information about warmth retention property will be transferred to house robot, and he will remind the user of taking on or off clothes according to the weather conditions and the information mentioned above.

\section{The Subject and Object from the Perspective of "Ubiquitous Computing”}

However, when the designer tries his best to reduce the complexity of the equipment to improve the efficiency and convenience of life by ubiquitous computing, he is also forced to pose challenges to human autonomy by this “ubiquitous” service.

According to Dilthey, "The outside world is an objective reality. I can perceive it only because it stands on the opposite side of my consciousness" (Zhang 2003, 6). Jean Piaget maintains a similar point of view when talking about the differentiation between subject and object in human history in his theory of "Genetic Epistemology.” He states that there is no distinction between subject and object in the nature world before the existence of human being. Even the early human beings are only treated as "spontaneous men" who lack self-awareness in that they cannot recognize what is "Ego" and what is "Non-Ego," neither can they distinguish between subject and object. With the development of technology, self-consciousness began to emerge in humans; they come to realize the nature they have built is different from themselves. In this way the subject distinguishes himself from the object. In other words, the "Initiative" of the Subject and the "Materiality" of the Object create a distance between the two, which makes the subject able to recognize the object (Liu 2008, 269).

A key criterion for the introduction and success of every-day technologies was the loss of problems in their handling and their ever more easy use (Wiegerling 1989, 1-4). However, only by perceiving the existence of the technology can we make a judgement of it. That is, only when we notice something can we have the chance to guide or control it; only when we know the consequence of a behavior can we be responsible for it. Yet ubiquitous computing is a quite different. Some simple smart devices are embedded into daily lives instead of a bulky computer. Without immediate and visible impact and clear function, the criteria to judge this new technology will be a problem. The so-called technology will be "ubiquitous" and "transparent." Human are no longer as an observer, standing outside the technological world, making an observation, an assessment, guidance or control of technology; but become a participant, "entangled" in the technological world. For humans who are regarded as the subject in the technological world, things from the outside world will be marked with the imprint of man's thought, in the process of technological development. As for the object of the 
technological world will always be the same case. By the reconstruction of technology, "human's original will" will be also changed, being marked with the purpose of technology systems. The distance between the subject and the object will be likely to be "swap away" in consideration of the cases that mentioned above. Or to put it in another way, there will not be clear boundaries between the subject and the object. The ambiguity between the subject and object of ubiquitous computing will inevitably change human cognition. In this case, making an assessment of technology means judging ourselves, and controlling the development of technology means limiting the development of human beings. Thus, how to evaluate and control the ubiquitous computing from the subject and object Perspective is the first ethical dilemma to be solved.

\section{Technological Interventions Affect Human Autonomy}

\subsection{Technology Addiction and the Loss of Self-Discipline}

"Technology addiction" describes a recent phenomenon that man is obsessed with technology and fails to get rid of it because of immersing in the benefits of technology for a long time. In the era of high-rapid development of technology, information becomes important and essential. For one thing, human beings access information through all kinds of ways. For another thing, the thirst for information increases sharply. Ubiquitous computing with its mass of an unlimited supply of information and service fulfills the desire of human for new information. However, the desire for new information is all right but how to accept and process the information correctly should be in the light of certain regulations. The stress in real world will inevitably result in frustration and discontent. When the frustration and discontent can hardly be resolved in the real world, people will try to seek comfort from the spirit world or virtue world, which can be provided by ubiquitous computing. In this virtual space, man will have a different identity from the real world. Man can let off steam, saying whatever they want and set up a "refuge" for spirit. It is the unprecedented freedom that provides "fertile soil" for the behavioral and psychological addiction. The only thing man can rely on is the self-discipline in his minds. However, man gets "comfort" from information space filled with confidence in the virtual world, indulging in such world and achieving satisfaction. However, the self-discipline in the real world will be easily left behind.

According to Kant, "Self-discipline is freedom." When man keeps the idea that "ubiquitous computing brings us unprecedented convenience and unrestricting, that is freedom," the results will be probably on the contrary. If man loses the ability of self-discipline, "he will be destined to pay the price for this freedom, which means freedom without limitations” (Li 2002, 144-8).

\subsection{Technology Dependence and the Degradation of Human Capacities}

"Human capacities" refers to the subject abilities of human beings. Despite Kant states his "Practical Reason" from the perspective of moral, he still emphasizes that practical reason is higher than theoretical reason by saying "As existence, man is able to self-created." Marx makes some addition on the basis of Kant's statement, "subject capacities include two elements: physiological structure and talent, which are inherent in the sense of human; there are also some capacities acquired through historical inhabitation, social communication, absorption and digest of other culture." With the two kinds of capacities, man began to be aware of the world (Sun 1996, 44-48).

In the stage of Ambient Intelligence, there will be not only various devices as hardware support, but also a powerful data system. The system can self-organize, self-manage, and even make decisions on their own 
according to the likes and dislikes of the users, in order to provide the users with personalized services. In the system, "Likes and dislikes or the needs of the users will be encodes in data and stored as specific user models" (Xu 2003, 1043), which must be remarked with the ideas of its designers. As a user, one is in a passive position. He can just accept the preferences, which has already arranged by others. There is no doubt that this passively acceptance will degrade one's creativity. Being accustomed to accept will result in the deterioration of thinking, judgment, discernment, and abilities.

Just think about the fact in daily life. When the user opens his phone to search information, the "residues traces" he did last time will come to him as "help;” when the user pays attention to writing papers, messages will appear on the screen to remind him of protection eyes. Some day if the user wants to take a vacation, he just needs to "tell" the system his time and destination, and the system will make a detailed and complete schedule for him, including hotels, flights, maps, even local newspaper etc. Will such kind of convenience make him cheerful or worried? Just thinking about this convenience from another perspective, human's ability to be aware and transform the world will gradually degrade with such convenience.

\subsection{The Reversal of the End and the Means Caused by the Fuzziness of Man-Machine Interface}

As Kant says in his Moral Law, "Man is the end.” Technology is just treated as means or conditions for human in the development process. It adapts to the nature of mankind, to the nature of material, and to the relationship between man and nature. Along with the "marriage" of the technology and science, intelligent technology (e.g., pervasive computing) has penetrated gradually into every corner of daily life. Man is faced with a "super world" which is equipped with embedded devices, smart devices, and wearable devices. Technology will no longer transform the world according to the will of human beings. It tries to manifest their own strength, just like the way of human beings (Liu 2005, 96-100). Technology has become the "agent" of human and tries to do the same work instead of man. Compared with the object (machine), man will be more and more incompetent. The purpose of overcoming the limitation of their own through technology turns out to be a negotiation of human himself. In front of human stands a world filled with tools. This will make man find out that he is not the only independent power to change the world any more. The distinction between human and machine becomes unobvious.

The fuzziness of man-machine interface causes a reversal of the end and the means. If technology can act for most of the work of human beings, the power of human will be weakened, however, that of technology will be gained. Technology can follow its own logic to realize its ends. Modern technology is now expanding itself like a Superman. It is now fighting for a higher status in the relationship between man and nature. In other words, human endow technology with the nature of human, but has been remarked with the nature of material. Due to the addiction to technology, the spirit of human will be controlled. Because of the dependence of technology, the physical abilities of human will deteriorate. When technology turns out to be a Superman, man will also lose the autonomy, which is the foundation of freedom. If things continue this way, human will no longer be the masters of the world, but becomes the means and the objects of technology.

\section{Conclusion}

The development of technology leads man into the era of ubiquitous computing. With its powerful and various features, it connects everybody in the world as a whole. Simultaneously, it will influence human's behavior, together with cultural background and the living environment. Confronted with such high-technology 
(e.g., ubiquitous computing), one should look into the possible ethical problems in the face, and make ethical reflection and criticism on technology.

Firstly, human beings should know "what." That is, what on earth does man want to obtain from technology? Ziemar refers to technology as "the freedom of material." Most philosophers of technology like Kapp and Ziemar, who work as engineers, show defense and worship of technology. People are always enjoying themselves in technological world and forget to ask for the essence of technology. It is undoubted that technology brings convenience and quickness, but one will give up thinking if devices can help him think. One will be reluctant to ask others for help when any data can be found on screen. One will lose trust to each other and only be willing to open his heart to machines. In the end, man will be the machine who uses machines. This seems not to be the situation that man really wants. What human really wants is just to improve the ability of thinking and adaption, to ease the intensity of the overload working, to have more time getting on well with relatives. It also ought to be the content of ubiquitous computing.

Secondly, human beings should think about "how." That is, how to realize the original purpose that one designs technology with potential dangers. Therefore, it is essential that human beings take a critical view of the development of ubiquitous computing and release some regulations to prevent technology from unretired expansion. However, according to Heidegger, "Boycotting technology blindly is unintelligent. Treating technology as devil is the lack of vision” (Sun 1996, 1239). Man is now using technology without awareness. Technology is now part of human's life. We must say both "Yes" and "No" to technology, which means we may let technical objects into our daily life and can also let them go. What is the criterion of "Yes" and "No?" The answer seems hard to find in conventional ethics, as only human beings are regarded as moral subjects and only the relationship between humans instead of the outside world is considered in conventional ethics. In the ethics of responsibility, Hans Jonas extends the objects to the entire biosphere, trying to concern the objects both now and the future. In the context of ubiquitous computing, we need to find a new ethical way to regulate the relationship between human beings and machine. That means, human beings should regard machines as moral subjects, concern the role machine plays, and keep harmonious relationship.

Technology comes into people's life, work, behavior, thoughts, and consciousness without being realized. One should not drift, nor be submissive. Instead, one can keep the "gap" between the subject and the object, searching for a new ethical regulation to keep harmony between himself and technology. Only by this means can man hold his "territory" under the "attack" of technology. Only in this way can human beings not become the object of technology. Man should take effective measures to avoid the phenomenon that human autonomy is robbed away by the autonomy of technology.

\section{Works Cited}

Cui, H. "Problems and Challenages of Google Glasses." China Invention \& Patent 5.1 (2014): 54.

Gunhild, L. "Funkchips Revolutionieren die Wirtschaft und Bringen Verbrauchern mehr Service.” Als Spione aber bedrohen sie die Privatsphäre. 2005. <http://www.zeit.de/2005/17/RFID/>.

Li, W. C. "Ethics of Technology and Metaphysics-on Hans Jonas' the Imperativ e of Responsibility." Studies in Dialectics of Nature 2.2 (2003): 41.

Li, Y. “The Formation Mechanism of Internet Addiction and Social Strategies.” Social Sciences in Guangdong 5 (2002): 144-8.

Liu, T. F. “The Inhuman Effects of Technological Development and Its Overcoming.” Zhejiang Social Sciences 4 (2005): 96-100.

Liu, W. Y. "Research of the Relationship Between Subject and Object in the Network Environment.” Social Sciences Review 12 (2008): 269. 
Shen, L. “Pervasive Computing.” Computer Engineering \& Science 27.7 (2005): 42.

Sun, X. M. "Marxism on the Subjectivity of Scientific Solutions.” Journal of Zhengzhou University (Philosophy and Social Science Edition) 4 (1996): 44-48.

Sun, Z. X. Terra: Anthology of Heidegger. Shanghai, IL: Sanlian Bookstore, 1996.

Wang, H. T., \& Song, L. H. "Pervasive Computing-New Generation Computing Mode and Idea.” Telecommunications Science 5.2 (2008): 66-71.

Wiegerling, K. “The Two Basic Questions of Ethics and the Loss of the Interface in Ambient Intelligence.” Die Erzählbarkeit der Welt. Lebach, 1989.

Wu, G. S. A Book on Classic Philosophy of Technology. Shanghai, IL: Profile of Shanghai Jiao Tong University Press, 2008.

Xu, G. Y. “Pervasive Computing.” Chinese Journal of Computers 9.9 (2003): 1043.

Zhang, S. Y. Introduction to Philosophy. Beijing, IL: Peking University Press, 2003.

Zhu, X. L. The Ethics Evaluation of Ubiquitous Computing. Dalian. IL: Department of Philosophy, Dalian University of Technology, 2009. 